Delft University of Technology

\title{
Large Scale Experimental Settlement Tests to Evaluate Structural Models for Tunnelling- Induced Damage Analysis
}

Dalgic, K. Deniz; Gulen, D. Burcu; Acikgoz, Sinan; Burd, Harvey; Hendriks, Max A.N.; Giardina, Giorgia; Ilki, Alper

DOI

10.1007/978-3-030-64518-2_20

Publication date

2021

Document Version

Final published version

Published in

Challenges and Innovations in Geomechanics - Proceedings of the 16th International Conference of

IACMAG - Volume 2

\section{Citation (APA)}

Dalgic, K. D., Gulen, D. B., Acikgoz, S., Burd, H., Hendriks, M. A. N., Giardina, G., \& Ilki, A. (2021). Large

Scale Experimental Settlement Tests to Evaluate Structural Models for Tunnelling-Induced Damage

Analysis. In M. Barla, A. Di Donna, \& D. Sterpi (Eds.), Challenges and Innovations in Geomechanics -

Proceedings of the 16th International Conference of IACMAG - Volume 2 (pp. 164-171). (Lecture Notes in

Civil Engineering; Vol. 126). Springer Science+Business Media. https://doi.org/10.1007/978-3-030-645182_20

Important note

To cite this publication, please use the final published version (if applicable).

Please check the document version above.

\section{Copyright}

Other than for strictly personal use, it is not permitted to download, forward or distribute the text or part of it, without the consent of the author(s) and/or copyright holder(s), unless the work is under an open content license such as Creative Commons.

\section{Takedown policy}

Please contact us and provide details if you believe this document breaches copyrights.

We will remove access to the work immediately and investigate your claim. 
Green Open Access added to TU Delft Institutional Repository

'You share, we take care!' - Taverne project

https://www.openaccess.nl/en/you-share-we-take-care

Otherwise as indicated in the copyright section: the publisher is the copyright holder of this work and the author uses the Dutch legislation to make this work public. 


\title{
Large Scale Experimental Settlement Tests to Evaluate Structural Models for Tunnelling-Induced Damage Analysis
}

\author{
K. Deniz Dalgic ${ }^{1(\bowtie)}$, D. Burcu Gulen ${ }^{2}$, Sinan Acikgoz ${ }^{2}$, \\ Harvey Burd ${ }^{2}$, Max A. N. Hendriks ${ }^{3,4}$, Giorgia Giardina ${ }^{3}$, \\ and Alper Ilki $^{5}$ \\ ${ }^{1}$ Department of Civil Engineering, Faculty of Engineering, Izmir Institute \\ of Technology, Urla 35430, Izmir, Turkey \\ korhandenizdalgic@iyte.edu.tr \\ 2 Department of Engineering Science, University of Oxford, \\ Parks Road, Oxford OX1 3PJ, UK \\ ${ }^{3}$ Faculty of Civil Engineering and Geosciences, Delft University of Technology, \\ Stevinweg 1, 2628 CN Delft, Netherlands \\ ${ }^{4}$ Department of Structural Engineering, Norwegian University of Science \\ and Technology, Rich. Birkelandsvei 1A, Trondheim, Norway \\ 5 Department of Civil Engineering, Istanbul Technical University, \\ Maslak 34469, Istanbul, Turkey
}

\begin{abstract}
Underground construction activities, such as tunnelling, cause local ground movements to occur. Nearby surface structures interact with the moving ground, potentially leading to building damage. Although it is understood that the severity of building damage is influenced by the façade opening ratio $(\mathrm{OpR})$ and the stiffness of the floors, experimental work in this area is lacking. This paper describes the specification and design of an experimental campaign on brick masonry buildings subjected to vertical base movements. The specimens are half-scale models of walls of two-storey buildings; models with different window arrangements and with/without floor slabs are examined. To design the experimental setup, 3D finite element analyses of the model walls were conducted. Key analysis results, presented in this paper, indicate how the examined structural properties (OpR, building weight, floor stiffness) are expected to influence the patterns of damage in the masonry. The finite element results are also used to design an instrumentation system comprising Fibre Bragg Grating (FBG) sensors and a digital image correlation (DIC) system. Data from the tests will support the formulation and validation of structural models for predicting tunnelling-induced damage in masonry buildings.
\end{abstract}

Keywords: Large scale testing $\cdot$ Settlement $\cdot$ Brick masonry $\cdot$ Monitoring 


\section{Introduction}

In current engineering practice, the potential risk of tunnelling-induced damage in masonry buildings is assessed by employing structural models ranging from simplified beam models (Burland and Wroth 1974) to complex finite element models (e.g. Giardina et al. 2013; Yiu et al. 2017; Dalgic et al. 2019).

To explore the limitations and advantages of such models, small-scale centrifuge experiments have recently been conducted (Ritter et al. 2017). While these experimental studies have led to an improved understanding of tunnel-soil-building interaction mechanisms, the experiments employed simplified building models, where masonry buildings are idealized with metallic beam or 3D printed plastic structures. Larger 1/10 scale experiments have also been conducted to explore the influence of deep excavations on masonry specimens (Laefer et al. 2011).

However, there remains a need for experiments, conducted at an appropriate scale, that preserve the key structural characteristics of actual buildings (material, geometry, in-situ stresses) such that realistic damage patterns can be observed and measured. To this end, an experimental campaign on half-scale masonry buildings, employing different façade openings and floor stiffnesses, has been designed. The paper describes the experimental setup to be employed in the tests, which is currently under construction. 3D finite element models of the wall specimens - developed to support the design of the experimental program - are also described. These models were used to develop the instrumentation system that will be used to measure the strains and displacements developed in the tests.

\section{Experimental Setup}

The experimental study is concerned with four $1 / 2$ scale specimens that are intended to represent historical masonry structures from Akaretler row houses built in the $19^{\text {th }}$ century in Istanbul (Ispir and Ilki 2013). The specimens will be tested by imposing vertical support movements to simulate ground movements induced by tunnelling and/or nearby deep excavations. As shown in Fig. 1, each specimen consists of two load-bearing brick masonry walls positioned parallel to each other, and reinforced concrete (RC) floors connecting these walls at two levels. The walls are built with halfscale solid clay bricks $(115 \times 57.5 \times 30 \mathrm{~mm})$. The height of each wall is approximately $3.2 \mathrm{~m}$ (two-storey height), the length is $5.6 \mathrm{~m}$ and the thickness of each panel is $0.115 \mathrm{~m}$ (length of one brick). To create a stress level at the base of the wall that is equivalent to a prototype structure, additional concrete masses are placed on the RC floors. Ground movements are simulated by deforming IPE 330 steel girders, which are located under the walls and pin-supported at three points. By pulling the edge pin support down in the vertical direction with screw jacks, a hogging-type settlement profile is generated.

The main test variables are the proportion (OpR) of the façade area taken up with openings and floor stiffness. Cases with OpR of 35\%, 20\% and $0 \%$ are considered to examine the effect of OpR. The specimen with three window openings (20\% OpR) and stiff floor is designated as the reference case. Another specimen with $20 \%$ OpR will 
also be tested with flexible RC floors. In addition, the effect of prior strengthening and retrofitting of this specimen will be examined. Strengthening and retrofitting will employ innovative methods in which a glass fibre-reinforced concrete material (Ates et al. 2019) is applied to the surface of the masonry. The experimental tests will be conducted in Duzce, Turkey during the spring and summer of 2020.

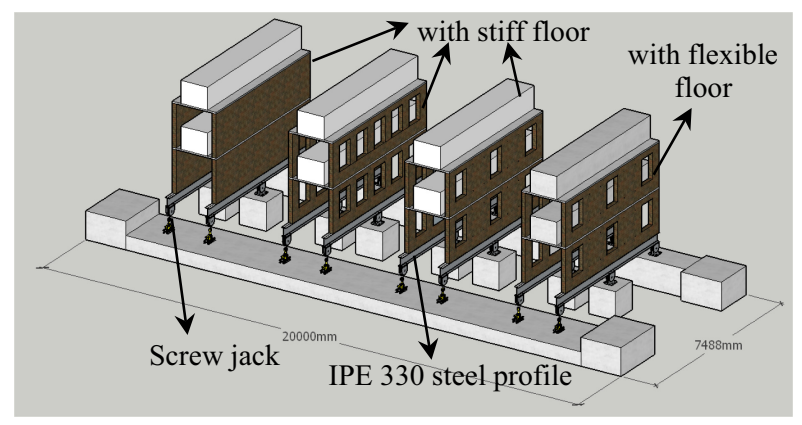

Fig. 1. Building specimens and test-setup

\section{3D Finite Element Models}

3D finite element models of the wall specimens were developed in DIANA 10.3 to support the experimental design and to predict the outcome of the experiments. The finite element models (Fig. 2a) employ curved shell elements to model the masonry walls, and structural solid elements to represent the IPE 330 steel girder that is used to

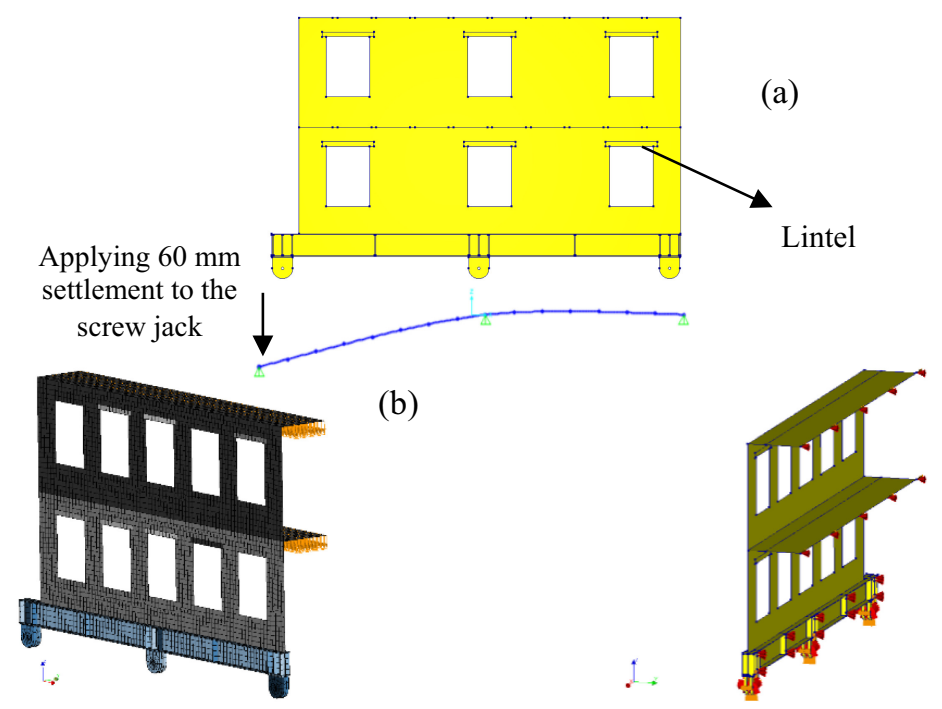

(c)

Fig. 2. 3D finite element model of the building specimens (a) model geometry with applied settlement profile (b) meshed model (c) demonstration of supports 
support the wall (Fig. 2b). To minimise the computational requirements, only half of the specimen is modelled; appropriate boundary conditions are assigned to the RC floors on the symmetry plane (Fig. 2c).

Three different load cases are considered: (i) self-weight of the test components, (ii) additional weight of concrete blocks placed on the RC floors and (iii) jack forces pulling down the IPE 330 girder to simulate tunnelling-induced settlements (Fig. 2a, 2b). The additional concrete blocks weigh about 7.8 tons per floor and the applied vertical movement at the tip of the screw jack is $60 \mathrm{~mm}$. This corresponds to a tunnelling scenario where a $12.2 \mathrm{~m}$ diameter tunnel is excavated at $25 \mathrm{~m}$ depth. The tunnel centreline is $9.2 \mathrm{~m}$ away from the left corner of the building, and the volume loss and trough width parameters are taken as $5 \%$ and 0.25 respectively. Prior to the imposed settlements, the vertical stress at the base of the wall is computed as approximately $0.20 \mathrm{MPa}$ for both prototype and model structures.

Material nonlinearity is considered for the masonry walls and the IPE 330 steel girders. To analyse the nonlinear response of the masonry walls, the total strain crack model is adopted (Giardina et al. 2013). The material properties assigned for the facades, floors, lintels and steel profiles are listed in Table 1. Some masonry material parameters (e.g. compressive and tensile strength) used for the facades have been adapted from a Technical Report (2019) published by the Ministry of Environment and Urbanization of Turkey. Mode-I tensile fracture energy and compressive fracture energy values were derived using the formulations suggested in DIANA Validation Report (2017) since they were not available in the Technical Report (2019). RC floors and lintels are modelled with linear elastic elements. The main body of the IPE 330 girder is modelled with the Von Mises plasticity model. However, the stiffening members and hinges are modelled as linear elastic. Numerical analyses were performed by considering both material and geometric nonlinearities. Modified Newton Raphson and Secant methods were used together with the energy convergence norm for the iterations.

Table 1. Assigned material properties for the façades, floors, lintels and steel profiles

\begin{tabular}{l|l|l|l|l}
\hline Element name & Facade & Floor & Lintel & Steel profile \\
\hline Material type & Masonry & RC & RC & IPE 330 \\
\hline Young's modulus $(\mathrm{MPa})$ & 3300 & 32000 & 27000 & 200000 \\
\hline Poisson's ratio & 0.15 & 0.2 & 0.2 & 0.3 \\
\hline Mass density $\left(\mathrm{kg} / \mathrm{m}^{3}\right)$ & 1800 & 2400 & 2400 & 7900 \\
\hline Tensile strength $\left(f_{\mathrm{t}}\right)(\mathrm{MPa})$ & 0.15 & & & \\
\hline $\begin{array}{l}\text { Mode-I tensile fracture energy }(\mathrm{N} / \mathrm{m}) \\
{\left[G_{\mathrm{ft}}=0.025\left(2 f_{\mathrm{t}}\right)^{0.7}\right]}\end{array}$ & 10 & & & \\
\hline Compressive strength $\left(f_{\mathrm{c}}\right)(\mathrm{MPa})$ & 2.75 & 30 & 16 & \\
\hline $\begin{array}{l}\text { Compressive fracture energy }(\mathrm{N} / \mathrm{m}) \\
{\left[G_{\mathrm{fc}}=15+0.43 f_{\mathrm{c}}-0.0036 f_{\mathrm{c}}^{2}\right]}\end{array}$ & 16000 & & & \\
\hline Yield stress $(\mathrm{MPa})$ & & & & \\
\hline
\end{tabular}


Additionally, a 3D line interface element (Table 2) based on the Coulomb friction model was used to represent the mechanical interaction between the top flange of the girder and the bottom of the masonry wall. The shear properties of the interface element is selected according to the results of the physical slip tests given by Rabbat and Russell (1985). No-tension behaviour with a large stiffness is considered in the normal direction.

Table 2. Assigned material properties for the line interface at the bottom of the masonry walls

\begin{tabular}{l|l}
\hline Element name & Interface \\
\hline Normal stiffness modulus, y $\left(\mathrm{N} / \mathrm{mm}^{3}\right)$ & 335 \\
\hline Shear stiffness modulus, $\mathrm{x}\left(\mathrm{N} / \mathrm{mm}^{3}\right)$ & 0.2 \\
\hline Shear stiffness modulus, z $\left(\mathrm{N} / \mathrm{mm}^{3}\right)$ & 0.2 \\
\hline Friction angle & 31.8 \\
\hline
\end{tabular}

\section{Finite Element Analysis Results}

Figure $3 \mathrm{a}$ shows a contour plot of the computed crack widths in the principal strain direction (with limits $0-5 \mathrm{~mm}$ ) for the reference specimen (OpR $=20 \%$ ) after the application of all of the loads (self-weight, additional weight and settlement). A maximum computed crack width of $9.9 \mathrm{~mm}$ is observed in this specimen. The damage concentrates at the ground storey, at the corners of openings.

For the specimen with $\mathrm{OpR}=35 \%$, the damage is also concentrated on the ground storey pier elements (Fig. 3b). More specifically, horizontal flexural cracks concentrate at the end of the piers close to the right and left ends of the wall due to a rocking-like mechanism. The specimen with $\mathrm{OpR}=0 \%$ shows a similar damage pattern to the $20 \%$ OpR specimen. However, less severe cracking is observed (max. Crack width is $4 \mathrm{~mm})$.

The influence of the magnitude of the vertical stresses on the computed damage profile is examined by removing the additional weights applied to the floors. The results show that reducing the vertical stresses in this way increases the magnitude of the maximum crack width of the wall for the $\mathrm{OpR}=20 \%$ specimen from $9.9 \mathrm{~mm}$ to $10.7 \mathrm{~mm}$ (Fig. 3d). However, the overall response and damage profile remains similar to the case where the additional weight is applied (Fig. 3a). To examine the effect of the $\mathrm{RC}$ floor stiffness on the wall damage, the RC floors are cut transversely in every $500 \mathrm{~mm}$ to reduce their flexural and axial stiffness (Fig. 3e). When the axially restraining effect of RC floors is minimized in this way the specimen demonstrates a beam-like response where significant damage concentrates at the upper storey spandrel walls (Fig. 3e); the maximum wall crack width, in this case, increases to $44.24 \mathrm{~mm}$. Another analysis in which the RC floors were omitted (not shown) revealed a similar response to Fig. 3e, validating the effect of reducing the floor stiffness. 

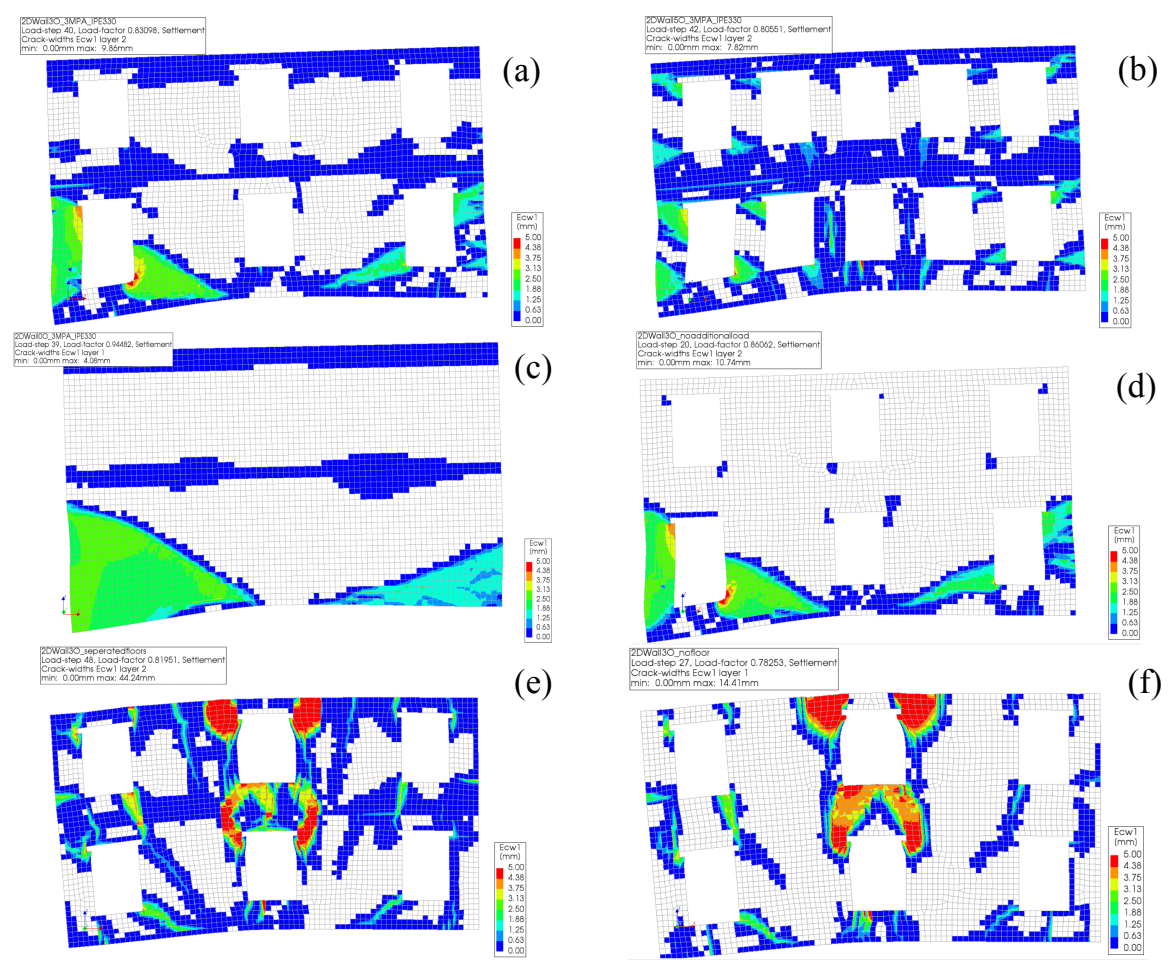

Fig. 3. 3D finite element analysis results in terms of crack widths in principal strain direction. Figs. (a), (d), (e) and (f) indicate cases with $\mathrm{OpR}=20 \%$; (b and c) indicates the cases with $\mathrm{OpR}=35 \%$ and $0 \%$. In Figs. (a), (b), (c), (e) and (f) all load cases (self-weight, settlement and additional weight) are applied. In Fig. (d) the additional weight is not applied. In Fig. (e) the RC floors are flexible. In Fig. (f) the RC floors are absent.

\section{FBG Sensors and DIC Instrumentation Design}

Detailed instrumentation of the experimental specimens is necessary to observe the modes of response that is discussed in the previous section. In particular, it is important to capture the distributed damage profile with measurements across the whole façade. Fibre Bragg Grating (FBG) sensors and Digital Image Correlation (DIC) systems will be employed in the tests to measure the average strains and displacements. The instrumentation has been designed to capture the overall displacements of the whole façade and the average strains across damaged structural elements on the basis of the previously-described finite element results (Fig. 3).

Fibre optic cables will be placed both on the inside (Fig. 4a) and outside surface (Fig. 4b) of the façade walls to evaluate the damage. Two fibre optic cables with 20 sensors each (located at a spacing of $1 \mathrm{~m}$, with a maximum strain limit of 1200 microstrain) will be used. The cables will be fixed to the surface of the specimen by clamps; they will provide average strain measurements between these fixing points 
(Acikgoz et al. 2018). Figure 4a shows the cable arrangement designed to capture the damage in the ground storey pier elements and the curvature in ground storey spandrel elements.

The outer surface of the façade wall (Fig. 4b) will also feature a regular grid of DIC targets, which will allow monitoring of displacements and interpolation of strains across pier and spandrel elements. These targets will be flat stickers $(10 \times 10 \mathrm{~cm})$ with a high contrast Bull's eye image. They will be monitored in 2D by three synchronised cameras located parallel to the wall at distances of 4-6 m. An additional camera will be placed perpendicular to the façade wall to measure out of plane movements (which are expected to be negligible). Relative DIC displacement measurements will be validated by FBG sensor measurements from nearby locations (see Fig. 4b).
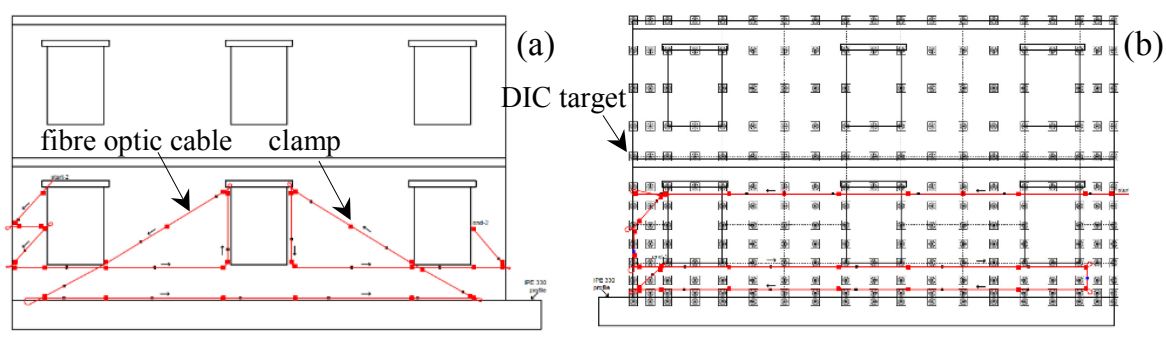

Fig. 4. Instrumentation designs; (a) FBG sensor instrumentation (inside surface of the wall) (b) FBG sensor and DIC target instrumentation (outside surface of the wall)

\section{Conclusions}

The paper describes an experimental campaign to investigate the deformations and damage induced in $1 / 2$ scale brick masonry building walls by the imposition of vertical ground movements to mimic nearby underground construction activities. A set of 3D finite element analyses, employed to support the development of the test walls and experimental protocols, is also described. Analyses were performed to consider a range of parameters and configurations such as; the area of façade openings, the inclusion of additional weights (which are applied on the floors to simulate the actual building weight due to scaling) and the stiffness of RC floors.

Results of the analysis of the specimen with an opening ratio of OpR $=35 \%$ indicated horizontal flexural cracks due to a pier rocking mechanism at the ground storey, while the finite element model of the specimen with $20 \%$ and $0 \%$ OpR indicated horizontal and diagonal cracking around the openings. When the flexural and axial stiffness of the RC floors were reduced in the finite element model, the computed crack widths increased significantly, leading to the predominant formation of cracks in the upper storey. The finite element models informed the development of instrumentation plans for FBG sensors and DIC targets, which will be employed to observe structural response during the tests. 
Acknowledgements. The activity presented in the paper is a part of an experimental project which is financially supported by Fibrobeton Company. The authors wish to thank Mr. Muhammed Marasli and Mr. Hasan Bilgin for their support.

\section{References}

Acikgoz, S., DeJong, M.J., Soga, K.: Sensing dynamic displacements in masonry rail bridges using 2D digital image correlation. Struct. Control Health Monit. 25(8), 1-24 (2018). https:// doi.org/10.1002/stc. 2187

Ates, A.O., Khoshkholghi, S., Tore, E., Marasli, M., Ilki, A.: Sprayed glass fiber-reinforced mortar with or without basalt textile reinforcement for jacketing of low-strength concrete prisms. ASCE J. Compos. Constr. 23(2), 04019003 (2019)

Burland, J.B., Wroth, C.P.: Settlement of buildings and associated damage. In: Proceedings of the Conference on Settlement of Structures, Cambridge, UK, pp. 611-654 (1974)

Dalgic, K.D., Hendriks, M.A.N., Ilki, A., Broere, W.: A two-stage numerical analysis approach for the assessment of the settlement response of the pre-damaged historic Hoca Pasha Mosque. Int. J. Archit. Heritage 13(5), 704-724 (2019). https://doi.org/10.1080/15583058. 2018.1469174

DIANA FEA BV and TU Delft. DIANA validation report for masonry modelling. TU Delft Structural Mechanics CiTG report CM-2016-17, Delft, Netherlands (2017)

Giardina, G., van de Graaf, A.V., Hendriks, M.A.N., Rots, J.G., Marini, A.: Numerical analysis of a masonry façade subject to tunnelling-induced settlements. Eng. Struct. 54, 234-247 (2013). https://doi.org/10.1016/j.engstruct.2013.03.055

Ispir, M., Ilki, A.: Behavior of historical unreinforced brick masonry walls under monotonic and cyclic compression. Arab. J. Sci. Eng. 38(8), 1993-2007 (2013). https://doi.org/10.1007/ s13369-013-0567-4

Laefer, D.F., Hong, L.T., Erkal, A., Long, J.H., Cording, E.J.: Manufacturing, assembly, and testing of scaled, historic masonry for one-gravity, pseudo-static, soil-structure experiments. Constr. Build. Mater. 25(12), 4362-4373 (2011)

Ministry of Environment and Urbanization of Turkey: Technical report: the principals regarding the determination of the risky buildings: Masonry and mixed structures, Ankara, Turkey (2019). (in Turkish)

Rabbat, B.G., Russell, H.G.: Friction coefficient of steel on concrete or grout. J. Struct. Eng. 111 (3), 505-515 (1985). https://doi.org/10.1061/(ASCE)0733-9445(1985)111:3(505)

Ritter, S., Giardina, G., DeJong, M.J., Mair, R.J.: Centrifuge modelling of building response to tunnel excavation. Int. J. Phys. Model. Geotech., 1-16 (2017). https://doi.org/10.1680/jphmg. 16.00053

Yiu, W.N., Burd, H.J., Martin, C.M.: Finite-element modelling for the assessment of tunnelinduced damage to a masonry building. Géotechnique 67(9), 780-794 (2017). https://doi.org/ 10.1680/jgeot.sip17.P.249 